\title{
Estrogen Plus Progestin and Risk of Venous Thrombosis
}

\begin{tabular}{l}
\hline Mary Cushman, MD, MSc \\
\hline Lewis H. Kuller, MD \\
\hline Ross Prentice, PhD \\
\hline Rebecca J. Rodabough, MS \\
\hline Bruce M. Psaty, MD, PhD \\
\hline Randall S. Stafford, MD, PhD \\
\hline Steven Sidney, MD \\
\hline Frits R. Rosendaal, MD, PhD \\
for the Women's Health Initiative \\
Investigators
\end{tabular}

V ENOUS THROMBOSIS (VT), INcluding deep vein thrombosis (DVT) and pulmonary embolus (PE), is a common disorder with an incidence of about 1 to 2 per 1000 person-years among adults. ${ }^{1}$ The risk of VT is higher with older age, in men compared with women, in blacks compared with whites, and in obese individuals, but VT is generally not associated with other classic atherogenic risk factors. ${ }^{2-4}$ Postmenopausal hormone therapy, such as estrogen with or without progestin, and selective estrogenreceptor modulators (tamoxifen and raloxifene) are associated with a 2- to 3-fold increased risk of VT. . $^{5-7}$

The association of postmenopausal hormone therapy with thrombosis risk has been confirmed in case-control studies, cohort studies, and clinical trials. ${ }^{8-15}$ To prevent VT among women considering hormone therapy use, it is important to define the most susceptible subgroups and whether any factors might attenuate the risk. In studies to date, it appears that the presence of factor V Leiden increases the risk of

\section{See also p 1581.}

Context Postmenopausal hormone therapy increases the risk of venous thrombosis. It is not known whether other factors influencing thrombosis add to this risk.

Objective To report final data on incidence of venous thrombosis in the Women's Health Initiative Estrogen Plus Progestin clinical trial and the association of hormone therapy with venous thrombosis in the setting of other thrombosis risk factors.

Design, Setting, and Participants Double-blind randomized controlled trial of 16608 postmenopausal women between the ages of 50 and 79 years, who were enrolled in 1993 through 1998 at 40 US clinical centers with 5.6 years of follow up; and a nested case-control study. Baseline gene variants related to thrombosis risk were measured in the first 147 women who developed thrombosis and in 513 controls.

Intervention Random assignment to $0.625 \mathrm{mg} / \mathrm{d}$ of conjugated equine estrogen plus $2.5 \mathrm{mg} / \mathrm{d}$ of medroxyprogesterone acetate, or placebo.

Main Outcome Measures Centrally validated deep vein thrombosis and pulmonary embolus.

Results Venous thrombosis occurred in 167 women taking estrogen plus progestin (3.5 per 1000 person-years) and in 76 taking placebo (1.7 per 1000 person-years); hazard ratio (HR), 2.06 (95\% confidence interval [Cl], 1.57-2.70). Compared with women between the ages of 50 and 59 years who were taking placebo, the risk associated with hormone therapy was higher with age: HR of $4.28(95 \% \mathrm{Cl}, 2.38-7.72)$ for women aged 60 to 69 years and $7.46(95 \% \mathrm{Cl}, 4.32-14.38)$ for women aged 70 to 79 years. Compared with women who were of normal weight and taking placebo, the risk associated with taking estrogen plus progestin was increased among overweight and obese women: HR of 3.80 (95\% Cl, 2.08-6.94) and 5.61 (95\% Cl, 3.12-10.11), respectively. Factor $\mathrm{V}$ Leiden enhanced the hormone-associated risk of thrombosis with a 6.69-fold increased risk compared with women in the placebo group without the mutation (95\% Cl, 3.09-14.49). Other genetic variants (prothrombin 20210A, methylenetetrahydrofolate reductase C677T, factor XIII Val34Leu, PAI-1 4G/5G, and factor $\checkmark$ HR2) did not modify the association of hormone therapy with venous thrombosis.

Conclusions Estrogen plus progestin was associated with doubling the risk of venous thrombosis. Estrogen plus progestin therapy increased the risks associated with age, overweight or obesity, and factor $\mathrm{V}$ Leiden.

JAMA. 2004:292:1573-1580

www.jama.com

VT associated with estrogen use to approximately 15 -fold. ${ }^{16,17}$ Clarification is needed on the effects of postmenopausal hormone therapy on thrombo-

Author Affiliations: Department of Medicine, University of Vermont, Burlington (Dr Cushman); Department of Epidemiology, University of Pittsburgh, Pittsburgh, Pa (Dr Kuller); Division of Public Health Sciences, Fred Hutchinson Cancer Research Center, Seattle, Wash (Dr Prentice and Ms Rodabough); Cardiovascular Health Research Unit, Departments of Medicine, Epidemiology, and Health Services, University of Washington, Seattle (Dr Psaty); Stanford Prevention Research Center, Program on Prevention sis in the presence of other VT risk factors, especially age, obesity, and purported protective factors, such as aspirin or statin use. ${ }^{14,18}$

Outcomes and Practices, Stanford University, Stanford, Calif (Dr Stafford); Division of Research, Kaiser Permanente, Oakland, Calif (Dr Sidney); and Department of Clinical Epidemiology, Leiden University Medical Center, Leiden, the Netherlands (Dr Rosendaal). The Women's Health Initiative Investigators are listed at the end of this article.

Corresponding Author: Mary Cushman, MD, MSc, University of Vermont, 208 S Park Dr, Suite 2, Colchester, VT 05446 (mary.cushman@uvm.edu) 
The Women's Health Initiative Estrogen Plus Progestin trial reported a 2.11-fold increased risk of VT among 16608 women randomized to combined estrogen plus progestin therapy compared with placebo. ${ }^{19}$ This initial article was based on locally adjudicated outcomes through April 30, 2002, with 5.2 years of follow-up. Active treatment in the trial was stopped early on July 8,2002 , following the recommendation of the external data and safety monitoring board, after determining that health risks exceeded benefits. In this article, we extend the previous findings for VT by evaluating centrally adjudicated incidence of VT through July 7, 2002, with an average follow-up of 5.6 years. We report the risk factors for VT and the interaction of postmenopausal hormone therapy and environmental and hemostatic risk factors.

\section{METHODS \\ Participants}

Detailed descriptions of the Women's Health Initiative have been published. ${ }^{20,21}$ Eligible women were between the ages of 50 and 79 years and were postmenopausal. Exclusion criteria related to presence of medical conditions associated with shortened survival or safety concerns, including level of triglycerides higher than $500 \mathrm{mg} / \mathrm{dL}$ $(5.65 \mathrm{mmol} / \mathrm{L})$. The protocol and consent forms were approved at each site by institutional review committees and all participants provided written informed consent. Due to published evidence of increased VT risk with postmenopausal hormone therapy use, as of July 1997 women with a previous history of DVT or PE were no longer enrolled.

This article is based on 16608 eligible women with an intact uterus at baseline who were randomly assigned in a double-blind fashion to receive estrogen plus progestin or matching placebo. Combined estrogen plus progestin was provided in a tablet containing $0.625 \mathrm{mg} / \mathrm{d}$ of conjugated equine estrogen and $2.5 \mathrm{mg} / \mathrm{d}$ of medroxyprogesterone acetate (PremPro, Wyeth
Ayerst, Philadelphia, Pa). At baseline, blood was drawn after a minimum 10hour fast.

Race/ethnicity was self-selected by participants from a list. Baseline medication use was ascertained by examining medication containers brought to study centers by participants. Aspirin use was defined as $80 \mathrm{mg} / \mathrm{d}$ or more for at least 30 days, and statin use was defined as any use in the previous 14 days. Overweight was defined as a body mass index (BMI) of between 25 and 30 and obesity as a BMI higher than 30. Body mass index was calculated as weight in kilograms divided by the square of height in meters.

\section{Events Ascertainment}

Study participants were followed up to assess clinical events every 6 months and had an annual in-clinic visit. Overall, 3.3\% of women were lost to follow-up (3.5\% in the estrogen plus progestin group and $3.0 \%$ in the placebo group). All hospital records were reviewed locally. Diagnoses of possible VT, including DVT and PE, first were reviewed by clinic center adjudicators using standardized criteria. ${ }^{21}$ These adjudicators were centrally trained and blinded to treatment assignment. Further review of locally adjudicated diagnoses was performed by central adjudication. The agreement between local and central adjudication was $89 \%$ for PE and 84\% for DVT. In cases of disagreement, a different central adjudicator reviewed the records and the local and central adjudication results for resolution. This article is based on the centrally adjudicated diagnoses through July 7, 2002.

The diagnosis of DVT was based on a physician diagnosis (hospital discharge summary with a diagnosis of DVT or outpatient treatment) and positive findings on doppler or duplex ultrasound, venogram, plethysmography, or isotope scan. The diagnosis of PE was based on a hospital discharge summary with a diagnosis of PE and positive findings on ventilationperfusion lung scan, pulmonary angiogram, or computed tomography. Pul- monary embolus was also confirmed if signs and symptoms suggested PE in the presence of a documented DVT. Events were classified as procedure-related if they occurred within 60 days of an invasive procedure. Study medication was stopped after a diagnosis of VT.

\section{Nested Case-Control Study}

A nested case-control study of biomarkers, treatment assignment, and risk of vascular outcomes was conducted after early findings indicated increased vascular risk in women taking estrogen plus progestin. All validated cases of VT that occurred between randomization and February 28, $2001(n=147)$ were included, by which time all women were more than 2 years from randomization. Controls were selected matched on age, randomization date, presence of baseline vascular disease specific to the case, and follow-up time. The controls selected to match cases of myocardial infarction and stroke were included in these analyses (513 total controls). For the women in this nested sample, available genomic DNA was analyzed using standard methods for factor $V$ Leiden $(n=615)$, prothrombin G20210A $(n=616)$, the thermolabile variant of methylenetetrahydrofolate reductase (C677T; $\mathrm{n}=619$ ), coagulation factor XIII Val34Leu (G100T; $n=615$ ), the $4 \mathrm{G} / 5 \mathrm{G}$ polymorphism of plasminogen activator inhibitor-1 (PAI-1; $\mathrm{n}=607$ ), and factor V HR2 (A4070G; $\mathrm{n}=614$ ).

\section{Statistical Analysis}

The main analyses used time-to-event methods (log-rank tests; Cox regression) based on intent-to-treat principles. For each outcome, the time-toevent for VT cases was the number of days from randomization to first diagnosis. For women without VT, the censoring time was the time from randomization to the earliest date of either death, loss to follow-up, or July 7, 2002. Outcome comparisons were presented as annualized rates and hazard ratios (HRs) with nominal (unadjusted for multiple outcomes) $95 \%$ confidence intervals (CIs). Overall VT was 
the primary outcome in these analyses, with secondary analyses assessing DVT and PE separately. Cox models were stratified by age, prior VT, and randomization status in the dietary modification trial (a concurrent trial that examined low-fat eating patterns). The HRs by time since randomization were calculated and tests of trends with time were performed in a Cox proportional hazards model incorporating a linear time $\times$ treatment interaction term. Sensitivity analysis was performed to assess the impact of stopping study pills during follow-up by censoring a woman from the analysis 6 months after nonadherence.

Pulmonary embolus was 1 of 7 outcomes included in a global index that was used in the early stopping recommendation of the trial. Because PE was relatively rare during follow-up, the nominal 95\% CIs reported herein are likely to be only slightly understated. Accounting for the 7 outcomes, the Bonferroni-adjusted 95\% CI for PE was 1.27 to 3.63 .

Analysis of associations of each genetic factor with risk of VT was performed using logistic regression, adjusting for age, randomization year, treatment assignment, and prior history of VT.

Interactions between hormone treatment assignment and baseline characteristics were examined by adding a product term between treatment and the characteristic to a model that included both variables as main effects. We tested for a value of zero for the product term coefficient tests to indicate a departure from a multiplicative interaction. To provide additional insight into the joint relationship of each genetic polymorphism and treatment with VT risk, we also tested an additive odds ratio model using a certain synergy index. ${ }^{22}$ Under an additive model, the increment above unity in the odds ratio for hormone therapy and a polymorphism combined is the sum of the increments above unity for treatment and the polymorphism separately. An additive model implies lower risk for the factors combined than does

Table 1. Baseline Characteristics Based on Development of Venous Thrombosis During Follow-up

\begin{tabular}{lcc}
\hline \multirow{2}{*}{ Characteristic } & \multicolumn{2}{c}{ No. (\%) of Participants* } \\
\cline { 2 - 3 } & $\begin{array}{c}\text { Without Venous } \\
\text { Thrombosis } \\
(\mathbf{n}=\mathbf{1 6} 365)\end{array}$ & $\begin{array}{c}\text { With Venous } \\
\text { Thrombosis } \\
(\mathbf{n}=\mathbf{2 4 3})\end{array}$ \\
\hline Age, mean (SD), y & $63.2(7.1)$ & $66.4(6.5)$ \\
\hline White & $13724(83.9)$ & $221(90.9)$ \\
\hline Body mass index, mean (SD)† & $28.4(5.9)$ & $30.7(6.3)$ \\
\hline Prior deep vein thrombosis or pulmonary embolus & $133(0.8)$ & $8(3.3)$ \\
\hline Current smoking & $1705(10.5)$ & $13(5.4)$ \\
\hline Diabetes & $720(4.4)$ & $14(5.8)$ \\
\hline Statin use & $1095(6.7)$ & $16(6.6)$ \\
\hline *Unless otherwise indicated. & & \\
†Calculated as weight in kilograms divided by the square of height in meters. & \\
\hline
\end{tabular}

a multiplicative model. Statistical analyses were performed using SAS statistical software (version 9, SAS Institute Inc, Cary, NC).

\section{RESULTS}

Baseline characteristics of women in the estrogen plus progestin and placebo groups were published. ${ }^{19}$ The distributions of potential VT risk factors were similar for both estrogen plus progestin and placebo. One third of the women were aged 50 to 59 years and $22 \%$ were aged 70 to 79 years. Eightyfour percent were white, $7 \%$ black, and one third of each were overweight or obese. Smoking (10\%) and diabetes (4\%) were uncommon. Statin use was reported by $7 \%$ and regular aspirin use by $20 \%$. Forty-three percent of women previously took oral contraceptives and $26 \%$ previously took estrogen plus progestin. There were 141 women $(<1 \%)$ with a prior history of VT. With a median follow-up of 5.6 years, 243 women developed VT. Of these 243 women, 124 had PE. Of the VT cases, 129 (53\%) had DVT alone diagnosed, while of those with PE, 53 (43\%) had recognized DVT. TABLE 1 shows the baseline characteristics of women who developed VT compared with those who did not.

As shown in TABLE 2, VT occurred in 167 women (3.5/1000 personyears) in the estrogen plus progestin group and 76 women (1.7/1000 personyears) in the placebo group (HR, 2.06; 95\% CI, 1.57-2.70). The HRs were simi- lar for DVT and PE. Twenty percent of cases of VT were procedure-related and these were not as strongly associated with estrogen plus progestin. Among 141 women who had VT prior to enrollment, there were 8 cases during follow-up-7 cases among women in the estrogen plus progestin group and 1 case in the placebo group (HR, 3.87; 95\% CI, 0.45-33.34).

Because about $40 \%$ of women stopped taking study pills, at least temporarily, during follow-up, the HRs may underestimate the association if there had been full adherence. In analyses wherein the follow-up for a woman was censored 6 months after stopping study medication or starting open-label hormone therapy, the resulting HR estimates were higher than those in Table 2 (VT: HR, 3.22; 95\% CI, 2.24-4.64; DVT: HR, 3.30; 95\% CI, 2.16-5.05; and PE: HR, 3.77; 95\% CI, 2.17-6.55).

The increased risk of VT was present in the year following randomization and persisted throughout follow-up (FIGURE 1). Results were similar for DVT and PE. The yearly HRs for VT were 4.01 in year $1 ; 1.97$ in year $2 ; 1.74$ in year $3 ; 1.70$ in year $4 ; 2.90$ in year 5 ; and 1.04 in year 6 or later. A test for trend in the HR over time showed diminishing risk of VT with increasing time from randomization $(P=.01)$; however, the incidence of VT appeared to increase among placebo-treated women in later years of follow-up. These yearly HRs did not differ materially, accounting for nonadherence. 
Compared with women aged 50 to 59 years and when adjusted for treatment assignment and BMI, women aged 60 to 69 years had an HR of 2.03 (95\% $\mathrm{CI}, 1.43-2.88)$ and women aged 70 to 79 years had an HR of $3.72(95 \% \mathrm{CI}$, 2.57-5.36). Considering age and treatment assignment, the highest incidence of VT was among older women assigned to the estrogen plus progestin group (TABLE 3). For each age group, the incidence of VT associated with estrogen plus progestin was increased by approximately 2 -fold.

The HR of VT adjusted for age and treatment assignment was 1.96 (95\% CI, 1.33-2.88) for overweight and 3.09 (95\% CI, 2.13-4.49) for obesity. The in- cidence rate of VT was highest among obese women assigned to the estrogen plus progestin group. These women had a nearly 6-fold higher risk than normal weight women who were taking placebo (TABLE 4). Within each BMI group, the HR of estrogen plus progestin compared with placebo was about 2-fold increased.

Among obese women aged 70 to 79 years, the incidence of VT was 8.9 per 1000 person-years in the estrogen plus progestin group and 4.6 per 1000 person-years in the placebo group. Among normal weight women aged 50 to 59 years, the incidence was 0.8 per 1000 person-years in the estrogen plus progestin group. There were not any cases of VT in the placebo group among women with a normal weight.

The HR of VT for the estrogen plus progestin group was not significantly altered by cigarette smoking, aspirin or statin use, history of cardiovascular disease prior to enrollment, prior use of postmenopausal hormone therapy or oral contraceptives, or any lipid measure (total cholesterol, low-density lipoprotein cholesterol, high-density lipoprotein cholesterol, and triglycerides; data not shown). The number of events among blacks and other ethnic groups was too small to evaluate ethnic-specific associations of estrogen plus progestin with VT.

Among the genetic variants, in analyses adjusted for age, randomization

Table 2. Venous Thrombosis Outcomes*

\begin{tabular}{|c|c|c|c|c|c|}
\hline \multirow[b]{2}{*}{ Outcome } & \multicolumn{2}{|c|}{ Estrogen + Progestin $(n=8506)$} & \multicolumn{2}{|c|}{ Placebo $(n=8102)$} & \multirow[b]{2}{*}{$\begin{array}{c}\text { Adjusted HR } \\
(95 \% \mathrm{Cl}) \dagger\end{array}$} \\
\hline & $\begin{array}{l}\text { No. of } \\
\text { Cases }\end{array}$ & $\begin{array}{l}\text { Annualized Rate/ } \\
1000 \text { Person-Years }\end{array}$ & $\begin{array}{l}\text { No. of } \\
\text { Cases }\end{array}$ & $\begin{array}{l}\text { Annualized Rate/ } \\
1000 \text { Person-Years }\end{array}$ & \\
\hline Venous thrombosis $\ddagger$ & 167 & 3.5 & 76 & 1.7 & $2.06(1.57-2.70)$ \\
\hline Deep vein thrombosis & 123 & 2.6 & 59 & 1.3 & $1.95(1.43-2.67)$ \\
\hline Pulmonary embolus & 86 & 1.8 & 38 & 0.8 & $2.13(1.45-3.11)$ \\
\hline Nonprocedure-related & 125 & 2.6 & 46 & 1.0 & $2.54(1.81-3.56)$ \\
\hline Deep vein thrombosis & 87 & 1.8 & 40 & 0.9 & $2.04(1.40-2.97)$ \\
\hline Pulmonary embolus & 65 & 1.4 & 23 & 0.5 & $2.67(1.66-4.29)$ \\
\hline Procedure-related & 27 & 0.6 & 23 & 0.5 & $1.09(0.63-1.91)$ \\
\hline Deep vein thrombosis & 25 & 0.5 & 14 & 0.3 & $1.64(0.85-3.17)$ \\
\hline Pulmonary embolus & 16 & 0.3 & 12 & 0.3 & $1.24(0.59-2.63)$ \\
\hline
\end{tabular}

Abbreviations: $\mathrm{Cl}$, confidence interval; $\mathrm{HR}$, hazard ratio.

*The mean (SD) follow-up time was 5.7 (1.4) years for the estrogen plus progestin group and 5.6 (1.3) years for the placebo group.

+Values are from Cox proportional hazards models and are adjusted for age, prior disease, and randomization group in the dietary modification trial.

flnformation on whether an event was procedure-related or not was missing for 22 cases.

Figure 1. Cumulative Hazard of Venous Thrombosis, Deep Vein Thrombosis, and Pulmonary Embolus

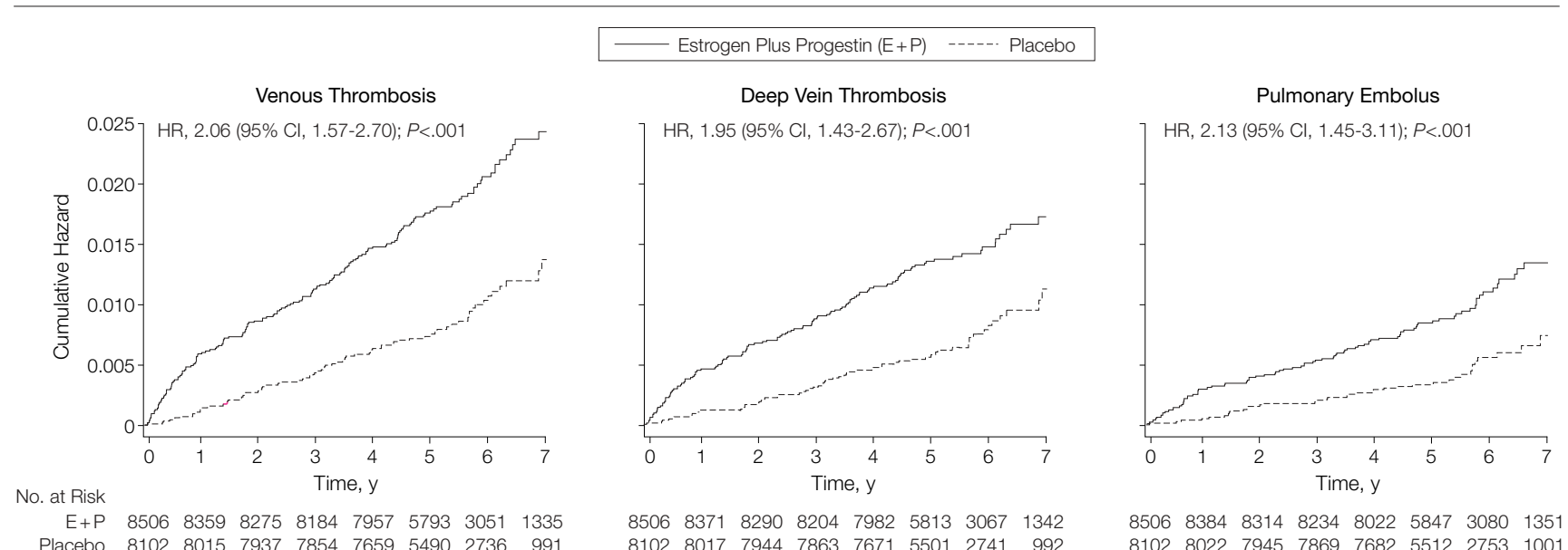

Placebo $810280157937785476595490 \quad 2736 \quad 991$

$\mathrm{Cl}$ indicates confidence interval; $\mathrm{HR}$, hazard ratio. 
Table 3. Age-Specific Incidence of Venous Thrombosis

\begin{tabular}{|c|c|c|c|c|c|c|}
\hline & & & & line Age, y & & \\
\hline & & $50-59$ & & & & 79 \\
\hline & Placebo & $\begin{aligned} & \text { Estrogen } \\
&+ \text { Progestin } \\
&\end{aligned}$ & Placebo & $\begin{array}{l}\text { Estrogen } \\
+ \text { Progestin }\end{array}$ & Placebo & $\begin{aligned} & \text { Estrogen } \\
+ & \text { Progestin }\end{aligned}$ \\
\hline No. of cases & 13 & 32 & 38 & 76 & 25 & 60 \\
\hline Annualized rate/1000 person-years & 0.8 & 1.9 & 1.9 & 3.5 & 2.7 & 6.2 \\
\hline $\mathrm{HR}(95 \% \mathrm{Cl})^{*}$ & 1.00 & $2.27(1.19-4.33)$ & $2.31(1.23-4.35)$ & $4.28(2.38-7.72)$ & $3.37(1.72-6.60)$ & $7.46(4.32-14.38)$ \\
\hline
\end{tabular}

Table 4. Incidence of Venous Thrombosis by Body Mass Index

\begin{tabular}{|c|c|c|c|c|c|c|}
\hline & \multicolumn{6}{|c|}{ Body Mass Index* } \\
\hline & \multicolumn{2}{|r|}{$<25$} & \multicolumn{2}{|c|}{$25-30$} & \multicolumn{2}{|c|}{$>30$} \\
\hline & Placebo & $\begin{aligned} & \text { Estrogen } \\
+ & \text { Progestin }\end{aligned}$ & Placebo & $\begin{aligned} & \text { Estrogen } \\
+ & \text { Progestin }\end{aligned}$ & Placebo & $\begin{aligned} & \text { Estrogen } \\
+ & \text { Progestin }\end{aligned}$ \\
\hline No. of cases & 13 & 24 & 24 & 59 & 38 & 83 \\
\hline Annualized rate/1000 person-years & 0.9 & 1.6 & 1.5 & 3.5 & 2.5 & 5.1 \\
\hline HR (95\% Cl)† & 1.00 & $1.78(0.91-3.51)$ & $1.63(0.83-3.20)$ & $3.80(2.08-6.94)$ & $2.87(1.52-5.40)$ & $5.61(3.12-10.11)$ \\
\hline
\end{tabular}

year, previous VT, and treatment assignment, only factor V Leiden was associated with the risk of VT, with a 2.6-fold increased risk among heterozygotes, and a 7.5-fold increased risk among homozygotes (TABLE 5). There was a suggestion of reduced VT risk associated with the homozygous factor XIII variant, but this was also true for the thermolabile variant of MTHFR, which, if anything, is expected to increase risk. Because several gene variants are less common among nonwhites, whites were analyzed separately and results did not differ materially.

FIGURE 2 shows the association with VT of genetic conditions in combination with placebo or estrogen plus progestin. For women with factor V Leiden who were taking estrogen plus progestin, the data were consistent with either a multiplicative odds ratio model $(P=.71)$ or an additive odds ratio model $(P=.50)$. Restricting analysis to white women, these significance levels were .74 and .44 , respectively. The odds of VT among women taking estrogen plus progestin who had factor V Leiden was slightly higher in white women than in
Table 5. Association of Genetic Variants With Venous Thrombosis

\begin{tabular}{|c|c|c|c|}
\hline Genetic Variant & No. (\%) of Controls & No. (\%) of Cases & OR $(95 \% \mathrm{Cl})^{*}$ \\
\hline $\begin{array}{l}\text { Factor V Leiden } \\
\text { GG }\end{array}$ & 455 (95.4) & $119(86.2)$ & 1.0 \\
\hline$\overline{\mathrm{GA}}$ & $21(4.4)$ & $17(12.3)$ & $2.6(1.3-5.2)$ \\
\hline$\overline{A A}$ & $1(0.2)$ & $2(1.4)$ & $7.5(0.6-87.8)$ \\
\hline $\begin{array}{l}\text { Prothrombin } 20210 \\
\text { GG }\end{array}$ & $458(95.8)$ & $133(96.4)$ & 1.0 \\
\hline$\overline{A G}$ & $20(4.2)$ & $5(3.6)$ & $0.8(0.3-2.2)$ \\
\hline $\mathrm{AA}$ & 0 & 0 & \\
\hline $\begin{array}{c}\text { MTHFR } \\
\text { CC }\end{array}$ & $204(42.5)$ & $70(50.4)$ & 1.0 \\
\hline$\overline{\mathrm{CT}}$ & $213(44.4)$ & $56(40.3)$ & $0.8(0.5-1.2)$ \\
\hline$\pi$ & $63(13.1)$ & $13(9.4)$ & $0.6(0.3-1.2)$ \\
\hline $\begin{array}{l}\text { Factor XIII } \\
\text { GG }\end{array}$ & 255 (53.5) & 75 (52.2) & 1.0 \\
\hline$\overline{\text { GT }}$ & $192(40.3)$ & $60(43.5)$ & $1.1(0.7-1.7)$ \\
\hline$\pi$ & $30(6.3)$ & $6(4.3)$ & $0.6(0.3-1.7)$ \\
\hline $\begin{array}{l}\mathrm{PAl}-1 \\
4 \mathrm{G} / 4 \mathrm{G}\end{array}$ & $119(25.4)$ & $37(26.8)$ & 1.0 \\
\hline $4 \mathrm{G} / 5 \mathrm{G}$ & 248 (52.9) & 68 (49.3) & $0.8(0.5-1.2)$ \\
\hline $5 G / 5 G$ & $102(21.7)$ & $33(23.9)$ & $1.0(0.6-1.8)$ \\
\hline $\begin{array}{l}\text { Factor V HR2 } \\
\text { AA }\end{array}$ & $421(88.4)$ & 124 (89.9) & 1.0 \\
\hline$\overline{A G}$ & 52 (10.9) & $13(9.4)$ & $0.8(0.4-1.6)$ \\
\hline GG & $3(0.6)$ & $1(0.7)$ & $1.0(0.1-10.1)$ \\
\hline
\end{tabular}

Abbreviations: $\mathrm{Cl}$, confidence interval; OR, odds ratio.

*Adjusted for age, year of randomization, prior venous thrombosis, and treatment assignment.

the overall group (OR, 8.53; 95\% CI, Val34Leu appeared to modulate the 3.78-19.23). For the other gene vari- risk associated with estrogen plus proants, only homozygous factor XIII gestin. 


\section{COMMENT}

Results from this randomized clinical trial of estrogen plus progestin in healthy postmenopausal women have further documented the increased risk of VT, including both DVT and PE, among women taking estrogen plus progestin. Results are consistent with previous studies of unopposed estrogen, estrogen plus progestin, and selective estrogen-receptor modulators. ${ }^{5-7,23}$ Considering other vascular outcomes of estrogen plus progestin in this study, VT accounted for the greatest number of excess events with estrogen plus progestin. Based on projections for 10 years for 1000 women taking estrogen plus progestin, the estimated excess number of events is 18 for VT, 6 for coronary heart disease, ${ }^{24}$
8 for invasive breast cancer, ${ }^{25}$ and 8 for stroke. ${ }^{26}$

Several conclusions may be made based on these findings. The increased risk of VT was highest in the first year of therapy, but continued through 5 years of treatment. This is consistent with most reports, ${ }^{9,14}$ but inconsistent with studies that suggested no increased risk after the first year of treatment. ${ }^{11,13}$ In agreement with findings in the general population, ${ }^{2-4}$ the risk of VT increased with age and obesity in this trial. While obese women or those aged 70 to 79 years had a similar relative risk of VT with estrogen plus progestin as thinner and younger women, there was a substantially higher number of cases of thrombosis in these groups due to their higher baseline risk.

Figure 2. Risk of Venous Thrombosis by Presence of Genetic Variants and Randomized Treatment Assignment

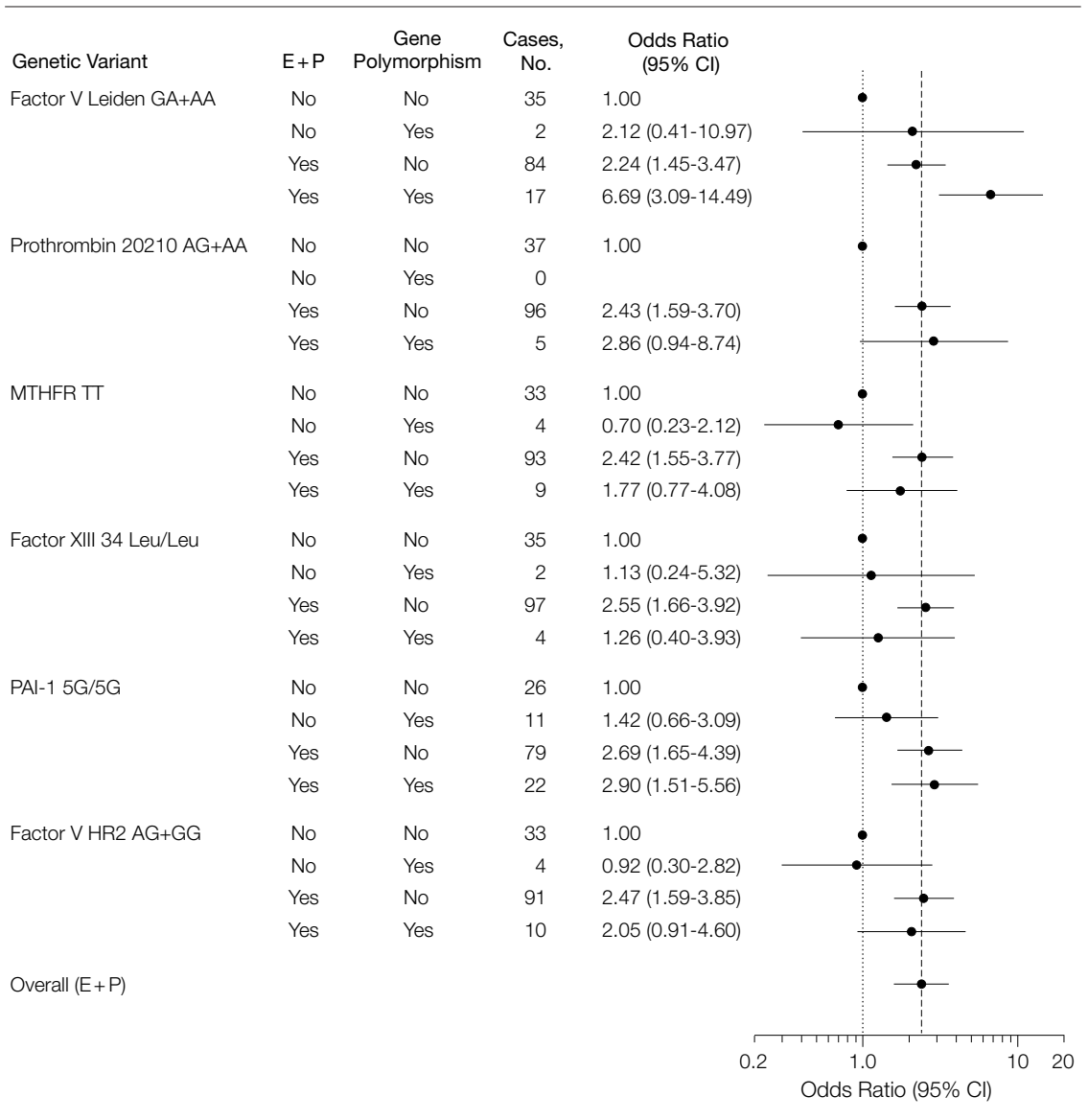

Dotted vertical line indicates the $\mathrm{OR}$ of venous thrombosis with $\mathrm{E}+\mathrm{P}$ in the nested case-control sample. $\mathrm{Cl}$ indicates confidence interval; $E+P$, estrogen plus progestin.

1578 JAMA, October 6, 2004—Vol 292, No. 13 (Reprinted)

Among women aged 70 to 79 years, the projected 10-year risk of VT was 6\% with estrogen plus progestin. For women aged 50 to 59 years, the age at which women might currently be considering postmenopausal hormone therapy use, the projected 5-year risk of estrogen plus progestin in obese women was $1.4 \%$ compared with less than $0.5 \%$ in normal weight women. While a recent study reported that the combination of obesity and oral contraceptives synergistically increase the risk of VT, ${ }^{4}$ we are unaware of other studies assessing postmenopausal hormone therapy and obesity.

Use of estrogen plus progestin among women with prior VT should be discouraged in the absence of ongoing anticoagulation. Although there were only 141 participants with previous VT, the high risk of recurrence with estrogen plus progestin observed herein agrees with a previous trial documenting a 1.3year incidence of VT of $10.7 \%$ with estradiol plus norethistrone acetate among women with prior VT. ${ }^{27}$

Our data suggest the absence of a protective effect of aspirin or statins on VT risk among women taking estrogen plus progestin. In high-risk populations such as surgery patients, aspirin use may be an effective prophylaxis against VT, especially in combination with other methods. ${ }^{28,29}$ Among women with coronary artery disease in the Heart and Estrogen/progestin Replacement Study (HERS), aspirin use appeared to attenuate the risk of VT associated with estrogen plus progestin, with a relative risk of 1.68 among women taking aspirin and 4.23 among women not taking aspirin, however this difference was not statistically significant and confounders were not evaluated. ${ }^{15}$ Herein and in the HERS trial, statins did not specifically protect against estrogen plus progestinassociated VT, ${ }^{14}$ although there may be differences among statins that require further study. ${ }^{30}$

Among the genetic polymorphisms assessed herein, only factor $\mathrm{V}$ Leiden was related to risk of VT and it appeared to combine with estrogen plus 
progestin therapy to modify risk in an approximate multiplicative fashion. This finding agrees with previous findings from a case-control study ${ }^{17}$ and from combined results of 2 trials of women with established coronary heart disease. ${ }^{16}$ Based on our findings, we estimate that the absolute risk of VT among women taking estrogen plus progestin with heterozygous or homozygous factor $\mathrm{V}$ Leiden is $0.8 \%$ per year. Other studies estimated this rate as $2.9 \%$ per year in families affected by factor V Leiden and thrombosis, ${ }^{31}$ and $1.5 \%$ per year among women with coronary artery disease. ${ }^{16}$ Based on our findings, if unselected healthy women considering estrogen plus progestin therapy were screened for factor V Leiden to withhold treatment from women with the mutation, 795 women would need to be screened to prevent 1 episode of VT over 5 years of treatment.

Interactions observed herein for estrogen plus progestin with both environmental and genetic risk factors for VT were weaker than previously reported interactions of oral contraceptives with VT risk factors. For example, the associations of obesity ${ }^{4}$ and factor V Leiden ${ }^{7}$ with VT are greatly increased by oral contraceptives and modestly increased by estrogen plus progestin. While the prothrombin 20210 A variant greatly increases the risk associated with oral contraceptives, we did not observe this for estrogen plus progestin. It is possible that the lower estrogen dose in the regimen of estrogen plus progestin explains these differences, but it is also possible that these interactions are harder to detect in postmenopausal women due to their higher baseline risk of VT compared with younger women.

The strengths of this study include the randomized double-blind design and ascertainment of outcome events in a large group of women. The analysis was limited by power considerations for subgroup analyses, particularly those related to the nested case-control study that included only 147 cases of VT. However, apart from factor V Leiden and per- haps factor XIII Val34Leu, given the lack of evidence for associations of the genetic polymorphisms with VT, it is unlikely that a clinically relevant interaction of these genetic factors with estrogen plus progestin exists. Nonadherence to study medications appeared to attenuate the observed associations of the estrogen plus progestin regimen with VT. Therefore our risk estimates for all analyses are likely to be underestimates. Finally, the results herein apply to the hormone formulation studied. Other data suggest that associations of postmenopausal hormone therapy with VT do not differ by formulation (estradiol, conjugated estrogens, unopposed vs combined therapy). ${ }^{7,32}$ However, there is limited information on different formulations and their interactions with genetic risk factors for VT. Furthermore, the association of transdermal estrogen therapy with VT is controversial, $, 11,33$ and no studies have assessed druggene interaction.

In summary, there was an increased risk of VT among women assigned to estrogen plus progestin in the Women's Health Initiative clinical trial. Older age and obesity added to the risk associated with a regimen of estrogen plus progestin. Thinner and younger women were at low absolute risk of VT, although their risk was still 2-fold higher among women taking estrogen plus progestin compared with women taking placebo. Women with factor $\mathrm{V}$ Leiden, but not other genetic variants, were particularly susceptible to estrogen plus progestin-induced VT. The implications of these findings may be important for the use of postmenopausal hormone therapy in the treatment of menopausal symptoms among younger postmenopausal women.

Author Contributions: Dr Cushman had full access to all of the data in the study and takes responsibility for the integrity of the data and the accuracy of the data analysis

Study concept and design: Cushman, Kuller, Prentice, Psaty, Rosendaal.

Acquisition of data: Cushman, Kuller, Prentice, Stafford. Analysis and interpretation of data: Cushman, Kuller, Prentice, Rodabough, Psaty, Stafford, Sidney, Rosendaal.

Drafting of the manuscript: Cushman, Kuller, Prentice, Rosendaal.

Critical revision of the manuscript for important in- tellectual content: Kuller, Prentice, Rodabough, Psaty, Stafford, Sidney, Rosendaal.

Statistical expertise: Prentice, Rodabough, Stafford. Obtained funding: Kuller, Prentice, Psaty, Rosendaal. Administrative, technical, or material support: Cushman, Kuller, Prentice.

Women's Health Initiative Program Office: National Heart, Lung, and Blood Institute, Bethesda, Md: Barbara Alving, Jacques Rossouw, Linda Pottern, Shari Ludlam, Joan McGowan.

Clinical Coordinating Center: Fred Hutchinson Cancer Research Center, Seattle, Wash: Ross Prentice, Garnet Anderson, Andrea LaCroix, Ruth Patterson, Anne McTiernan, Barbara Cochrane, Julie Hunt, Lesley Tinker, Charles Kooperberg, Martin Mclntosh, C. Y. Wang, Chu Chen, Deborah Bowen, Alan Kristal, Janet Stanford, Nicole Urban, Noel Weiss, Emily White. Wake Forest University School of Medicine, WinstonSalem, NC: Sally Shumaker, Pentti Rautaharju, Ronald Prineas, Michelle Naughton. Medical Research Labs, Highland Heights, Ky: Evan Stein, Peter Laskarzewski. University of California, San Francisco: Steven Cummings, Michael Nevitt, Maurice Dockrell. University of Minnesota, Minneapolis: Lisa Harnack. McKesson BioServices, Rockville, Md: Frank Cammarata, Steve Lindenfelser. University of Washington, Seattle: Bruce Psaty, Susan Heckbert.

Clinical Centers and Investigators: Albert Einstein College of Medicine, Bronx, NY: Sylvia WassertheilSmoller, William Frishman, Judith Wylie-Rosett, David Barad, Ruth Freeman. Baylor College of Medicine, Houston, Tex: Jennifer Hays, Ronald Young, Jill Anderson, Sandy Lithgow, Paul Bray. Brigham and Women's Hospital, Harvard Medical School, Boston, Mass: JoAnn Manson, Julie Buring, J. Michael Gaziano, Kathryn Rexrode, Claudia Chae. Brown University, Providence, RI: Annlouise R. Assaf, Carol Wheeler, Charles Eaton, Michelle Cyr. Emory University, Atlanta, Ga: Lawrence Phillips, Margaret Pedersen, Ora Strickland, Margaret Huber, Vivian Porter. Fred Hutchinson Cancer Research Center, Seattle, Wash: Shirley A. A. Beresford, Vicky M. Taylor, Nancy F. Woods, Maureen Henderson, Robyn Andersen. George Washington University, Washington, DC: Judith Hsia, Nancy Gaba, Joao Ascensao. HarborUCLA Research and Education Institute, Torrance, Calif: Rowan Chlebowski, Robert Detrano, Anita Nelson, James Heiner, John Marshall. Kaiser Permanente Center for Health Research, Portland, Ore: Cheryl Ritenbaugh, Barbara Valanis, Patricia Elmer, Victor Stevens, Njeri Karanja. Kaiser Permanente Division of Research, Oakland, Calif: Bette Caan, Stephen Sidney, Geri Bailey, Jane Hirata. Medical College of Wisconsin, Milwaukee: Jane Morley Kotchen, Vanessa Barnabei, Theodore A. Kotchen, Mary Ann C. Gilligan, Joan Neuner. MedStar Research Institute/Howard University, Washington, DC: Barbara V. Howard, Lucile Adams-Campbell, Lawrence Lessin, Monique Rainford, Gabriel Uwaifo. Northwestern University, Chicago/ Evanston, III: Linda Van Horn, Philip Greenland, Janardan Khandekar, Kiang Liu, Carol Rosenberg. RushPresbyterian-St Luke's Medical Center, Chicago, III: Henry Black, Lynda Powell, Ellen Mason. Stanford Center for Research in Disease Prevention, Stanford University, Stanford, Calif: Marcia L. Stefanick, Mark A. Hlatky, Bertha Chen, Randall S. Stafford, Linda C. Giudice. State University of New York, Stony Brook: Dorothy Lane, Iris Granek, William Lawson, Gabriel San Roman, Catherine Messina. Ohio State University, Columbus: Rebecca Jackson, Randall Harris, Electra Paskett, W. Jerry Mysiw, Michael Blumenfeld. University of Alabama, Birmingham: Cora E. Lewis, Albert Oberman, James M. Shikany, Monika Safford, Brian K. Britt. University of Arizona, Tucson/Phoenix: Tamsen Bassford, Cyndi Thomson, Marcia Ko, Ana Maria Lopez. State University of New York, Buffalo: Jean Wactawski-Wende, Maurizio Trevisan, Ellen Smit, Susan Graham, June Chang. University of California at 
Davis, Sacramento: John Robbins, S. Yasmeen. University of California at Irvine, Orange: Allan Hubbell, Gail Frank, Nathan Wong, Nancy Greep, Bradley Monk. University of California, Los Angeles: Howard Judd, David Heber, Robert Elashoff. University of California at San Diego, LaJolla/Chula Vista: Robert D. Langer, Michael H. Criqui, Gregory T. Talavera, Cedric F. Garland, R. Elaine Hanson. University of Cincinnati, Cincinnati, Ohio: Margery Gass, Suzanne Wernke, Nelson Watts. University of Florida, Gainesville/ Jacksonville: Marian Limacher, Michael Perri, Andrew Kaunitz, R. Stan Williams, Yvonne Brinson. University of Hawaii, Honolulu: David Curb, Helen Petrovitch, Beatriz Rodriguez, Kamal Masaki, Santosh Sharma. University of lowa, lowa City/ Davenport: Robert Wallace, James Torner, Susan Johnson, Linda Snetselaar, Bradley VanVoorhis. University of Massachusetts/Fallon Clinic, Worcester: Judith Ockene, Milagros Rosal, Ira Ockene, Robert Yood, Patricia Aronson. University of Medicine and Den- tistry of New Jersey, Newark: Norman Lasser, Baljinder Singh, Vera Lasser, John Kostis. University of Miami, Miami, Fla: Mary Jo O'Sullivan, Linda Parker, R. Estape, Diann Fernandez. University of Minnesota, Minneapolis: Karen L, Margolis, Richard H. Grimm, Donald B. Hunninghake, June LaValleur, Sarah Kempainen. University of Nevada, Reno: Robert Brunner, William Graettinger, Vicki Oujevolk. University of North Caroina, Chapel Hill: Gerardo Heiss, Pamela Haines, David Ontjes, Carla Sueta, Ellen Wells. University of Pittsburgh, Pittsburgh, Pa: Lewis Kuller, Jane Cauley, N. Carole Milas. University of Tennessee, Memphis: Karen C. Johnson, Suzanne Satterfield, Raymond W. Ke, Stephanie Connelly, Fran Tylavsky. University of Texas Health Science Center, San Antonio: Robert Brzyski, Robert Schenken, Jose Trabal, Mercedes RodriguezSifuentes, Charles Mouton. University of Wisconsin, Madison: Gloria Sarto, Douglas Laube, Patrick McBride, Julie Mares-Perlman, Barbara Loevinger. Wake Forest University School of Medicine, Winston-
Salem, NC: Denise Bonds, Greg Burke, Robin Crouse, Mara Vitolins, Scott Washburn. Wayne State University School of Medicine/Hutzel Hospital, Detroit, Mich: Susan Hendrix, Michael Simon, Gene McNeeley.

Funding/Support: The Women's Health Initiative was funded by the National Heart, Lung and Blood Institute. Wyeth-Ayerst Research provided the study medications (active and placebo). Additional funding was provided by grant 2001.029 from the Netherlands Heart Foundation.

Role of the Sponsor: The National Heart, Lung, and Blood Institute participated in the design and conduct of the study, collection, management, analysis and interpretation of the data, and reviewed the manuscript. A National Heart, Lung, and Blood Institute representative served as a member of the Women's Health Iniative Steering Committee. Wyeth-Ayerst provided study pills but had no other role in the study. The Netherlands Heart Foundation provided funding, but had no other role in the study.

\section{REFERENCES}

1. White RH. The epidemiology of venous thromboembolism. Circulation. 2003;107(23 suppl 1):14-18.

2. Samama MM. An epidemiologic study of risk factors for deep vein thrombosis in medical outpatients: the Sirius study. Arch Intern Med. 2000;160: 3415-3420.

3. Tsai AW, Cushman M, Rosamond WD, Heckbert SR, Polak JF, Folsom AR. Cardiovascular risk factors and venous thromboembolism incidence: the Longitudinal Investigation of Thromboembolism Etiology. Arch Intern Med 2002:162:1182-1189.

4. Abdollahi M, Cushman M, Rosendaal FR. Obesity: risk of venous thrombosis and the interaction with coagulation factor levels and oral contraceptive use. Thromb Haemost. 2003;89:493-498.

5. Fisher B, Costantino JP, Wickerham DL, et al. Tamoxifen for prevention of breast cancer: report of the National Surgical Adjuvant Breast and Bowel Project P-1 Study. J Natl Cancer Inst. 1998;90:1371-1388. 6. Ettinger B, Black DM, Mitlak BH, et al. Reduction of vertebral fracture risk in postmenopausal women with osteoporosis treated with raloxifene: results from a 3-year randomized clinical trial. Multiple Outcomes of Raloxifene Evaluation (MORE) Investigators. JAMA. 1999;282:637-645.

7. Rosendaal FR, Helmerhorst FM, Vandenbroucke JP. Female hormones and thrombosis. Arterioscler Thromb Vasc Biol. 2002;22:201-210.

8. Daly E, Vessey MP, Hawkins MM, Carson JL, Gough $P$, Marsh S. Risk of venous thromboembolism in users of hormone replacement therapy. Lancet. 1996;348: 977-980.

9. Jick H, Derby LE, Wald Myers M, Vasilakis C, Newton KM. Risk of hospital admission for idiopathic venous thromboembolism among users of postmenopausal oestrogens. Lancet. 1996;348:981-983. 10. Grodstein F, Stampfer MJ, Goldhaber SZ, et al. Prospective study of exogenous hormones and risk of pulmonary embolism in women. Lancet. 1996;348: 983-987.

11. Perez-Gutthann S, Garcia-Rodriguez LA, Castellsague-Pique J, Duque-Oliart A. Hormone replacement therapy and risk of venous thromboembolism: population based case-control study. BMJ. 1997;314: 796-800.

12. Varas-Lorenzo C, Garcia-Rodriguez LA, Cattaruzzi C, Troncon MG, Agostinis L, Perez-Gutthann S.
Hormne replacement therapy and risk of hospitalization for venous thromboembolism: a populationbased study in southern Europe. Am J Epidemiol. 1998; 147:387-390.

13. Hoibraaten $E$, Abdelnoor $M$, Sandset PM. Hormone replacement therapy with estradiol and risk of venous thromboembolism - a population-based casecontrol study. Thromb Haemost. 1999;82:1218-1221. 14. Grady D, Wenger NK, Herrington D, et al. Postmenopausal hormone therapy increases risk for venous thromboembolic disease: the Heart and Estrogen/ progestin Replacement Study. Ann Intern Med. 2000; 132:689-696.

15. Hulley S, Furberg C, Barrett-Connor E, et al. Noncardiovascular disease outcomes during 6.8 years of hormone therapy: Heart and Estrogen/progestin Replacement Study follow-up (HERS II). JAMA. 2002;288: 58-66.

16. Herrington DM, Vittinghoff $E$, Howard TD, et al. Factor $V$ Leiden, hormone replacement therapy, and risk of venous thromboembolic events in women with coronary disease. Arterioscler Thromb Vasc Biol. 2002; 22:1012-1017

17. Rosendaal FR, Vessey M, Rumley A, et al. Hormonal replacement therapy, prothrombotic mutations and the risk of venous thrombosis. $\mathrm{Br} J \mathrm{Haematol}$ 2002;116:851-854

18. Ray JG, Mamdani M, Tsuyuki RT, Anderson DR, Yeo EL, Laupacis A. Use of statins and subsequent development of deep vein thrombosis. Arch Intern Med. 2001;161:1405-1410

19. Rossouw JE, Anderson GL, Prentice RL, et al. Risks and benefits of estrogen plus progestin in healthy postmenopausal women: principal results from the Women's Health Initiative randomized controlled trial. JAMA. 2002;288:321-333.

20. The Women's Health Initiative Study Group. Design of the Women's Health Initiative clnical trial and observational study. Control Clin Trials. 1998;19:61109.

21. Curb JD, McTiernan $A$, Heckbert $S R$, et al. Outcomes ascertainment and adjudication methods in the Women's Health Initiative. Ann Epidemiol. 2003;13: S122-S128.

22. Skrondal A. Interaction as departure from additivity in case-control studies: a cautionary note. Am J Epidemiol. 2003;158:251-258.

23. IBIS Investigators. First results from the Interna- tional Breast Cancer Intervention Study (IBIS-I): a randomised prevention trial. Lancet. 2002;360:817-824 24. Manson JE, Hsia J, Johnson KC, et al. Estrogen plus progestin and the risk of coronary heart disease. N Engl J Med. 2003;349:523-534.

25. Chlebowski RT, Hendrix SL, Langer RD, et al. Influence of estrogen plus progestin on breast cancer and mammography in healthy postmenopausal women: the Women's Health Initiative Randomized Trial. JAMA. 2003;289:3243-3253.

26. Wassertheil-Smoller S, Hendrix SL, Limacher $M$, et al. Effect of estrogen plus progestin on stroke in postmenopausal women: the Women's Health Initiative: a randomized trial. JAMA. 2003;289:2673-2684.

27. Hoibraaten E, Qvigstad E, Arnesen H, Larsen S, Wickstrom E, Sandset PM. Increased risk of recurrent venous thromboembolism during hormone replacement therapy-results of the randomized, doubleblind, placebo-controlled estrogen in venous thromboembolism trial (EVTET). Thromb Haemost. 2000;84: 961-967.

28. Antiplatelet Trialists' Collaboration. Collaborative overview of randomised trials of antiplatelet therapy-III: reduction in venous thrombosis and pulmonary embolism by antiplatelet prophylaxis among surgical and medical patients. BMJ.1994:308:235-246. 29. Prevention of pulmonary embolism and deep vein thrombosis with low dose aspirin: Pulmonary Embolism Prevention (PEP) trial. Lancet. 2000;355: 1295-1302.

30. Doggen CJ, Lemaitre RN, Smith NL, Heckbert SR Psaty BM. HMG CoA reductase inhibitors and the risk of venous thrombosis among postmenopausal women. J Thromb Haemost. 2004;2:700-701.

31. Middeldorp S, Meinardi JR, Koopman MM, et al. A prospective study of asymptomatic carriers of the factor $\mathrm{V}$ Leiden mutation to determine the incidence of venous thromboembolism. Ann Intern Med. 2001; 135:322-327.

32. Anderson GL, Limacher $M$, Assaf $A R$, et al. Effects of conjugated equine estrogen in postmenopausal women with hysterectomy: the Women's Health Initiative randomized controlled trial. JAMA. 2004;291: 1701-1712.

33. Scarabin PY, Oger E, Plu-Bureau G. Differential association of oral and transdermal oestrogenreplacement therapy with venous thromboembolism risk. Lancet. 2003;362:428-432. 